\title{
Aquatic invasive species rapid response planning partnerships in the Lake Champlain basin: Bridging international, political, social, and economic gaps"
}

\author{
Margaret D Modley* \\ Lake Champlain Basin Program, 54 West Shore Rd., Grand Isle, Vermont, 05458 USA
}

\begin{abstract}
The Lake Champlain Basin is threatened by several non-native invasive plant and animal species. The U.S. states of Vermont and New York, and the province of Quebec, Canada share the Lake Champlain watershed. The three jurisdictions work together to protect their water resources and implement Opportunities for Action, a long-term watershed management plan for the Basin. Together they recognise the need to control the introduction, spread, and impact of non-native invasive species in order to preserve the biological and ecological integrity of the Lake Champlain ecosystem independent of political borders. The Lake Champlain Basin Program Aquatic Nuisance Species Subcommittee is developing an invasive species rapid response action plan that addresses invasive species control and spread prevention in the Basin. A rapid response is an effort to contain and control non-native invasive species introductions while they are localised in a short amount of time, such as weeks or months, before they become established and more expensive to manage. Lake managers, policy makers, scientists, academics, and representatives of local watershed organisations from the three jurisdictions have shared information and data to foster the development of a comprehensive plan. Gaps in interstate and inter-jurisdictional laws and policy have been identified by reviewing all necessary permits for aquatic invasive species control methods. Examining the interface of law, policy, and permits aids in identifying regulatory and policy inadequacies, and opportunities for corrective legislation. Partnering among diverse organisations has allowed strategic invasive species rapid response planning that builds on managers' and policy makers' concerns, provides options, fosters inter-jurisdictional cooperation, and considers social, economic, and political impacts of invasive species management. The rapid response planning process identifies lead agencies from each of the three jurisdictions, recommends the formation of one governing body, and includes detailed steps of a rapid response process. The goal of the rapid response plan is to foster dialogue among permit applicants, scientists, and regulatory agencies, to ensure the fastest action possible. The Lake Champlain Basin invasive species rapid response planning process provides an applicable model for the United Nations Educational Scientific Organisation Hydrology for the Environment, Life, and Policy (HELP) basins around the world.
\end{abstract}

Keywords: aquatic invasive species, aquatic nuisance species, Lake Champlain, lake management, integrated water resource management, rapid response plan

\section{Introduction}

Non-native invasive plant and animal species cost state, federal, provincial, and local agencies millions of US dollars to manage annually. Invasive species are non-native species that cause economic and environmental harm. These species are harmful because once they become established they are free of natural predators and pests and often are able to thrive in a range of different habitats. Invasive species threaten recreational, cultural, historic, economic, and ecological resources by choking waterways, blocking water intake pipes, displacing native, rare, threatened and endangered species, transporting pathogens, and threatening fisheries.

According to the Non-indigenous Aquatic Nuisance Prevention and Control Act of 1990, aquatic nuisance species means, 'a non-indigenous species that threatens the diversity or abundance of native species or the ecological stability of infested waters, or commercial, agricultural, aquaculture, or recreational activi-

Revised paper. Originally presented at the symposium 'HELP in Action: Local Solutions to Global Water Problems - Lessons from the South' which was held at the Emperor's Palace, Johannesburg, South Africa from 4 to 9 November 2007.

* To whom all correspondence should be addressed.

푤 USA (802) 372-3213; fax: USA (802) 372-3233;

e-mail: mmodley@lcbp.org; ties dependent on such waters' (NANPCA, 1990). The National Aquatic Nuisance Species Task Force notes that aquatic invasive species include non-indigenous species that may occur in inland, estuarine and marine waters and that presently or potentially threaten ecological processes and natural resources. In addition to adversely affecting activities dependant on waters of the United States, some invasive species may cause adverse health effects on humans (US Federal ANS Task Force, 2005).

Invasive plants, animals, and pathogens are transported to new water bodies through a number of intentional and unintentional vectors. Some examples of invasive species vectors of introduction include fish stocking, canals, accidental release, bait bucket release, aquarium dumping, ballast water exchange, and transport of organisms on boats, trailers, and other recreational equipment. The early identification (early detection) and swift efforts to contain and control (rapid response) a new invasion or spread of an invasive species is more cost effective than long term management of an established species. However, watersheds that span interstate and international borders face challenges in developing management strategies that protect an entire basin.

The Lake Champlain Basin Program Technical Advisory Committee has an Aquatic Nuisance Species Subcommittee whose members are representative of the three governing bodies of Vermont, New York, and the Province of Quebec that make up the Lake Champlain Basin. The representatives include 


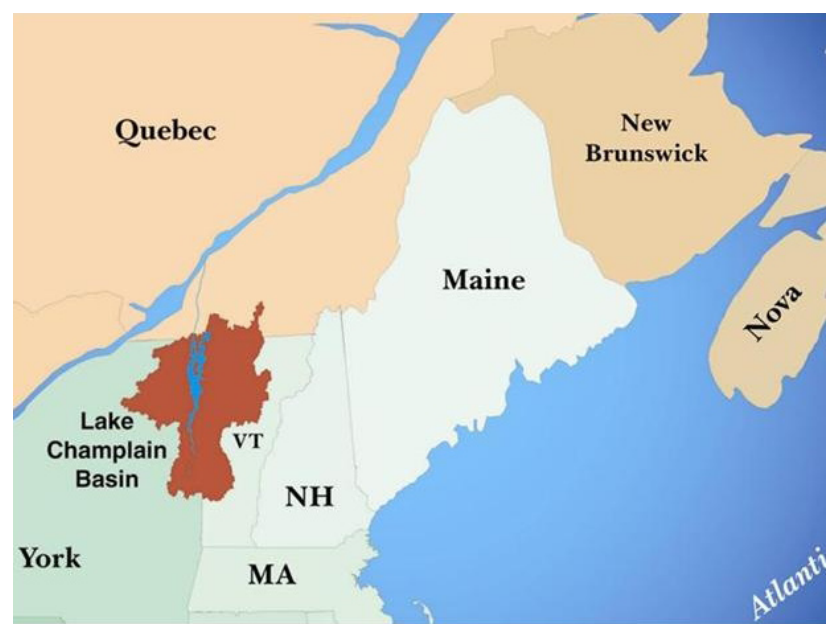

Figure 1

Location of the Lake Champlain Basin

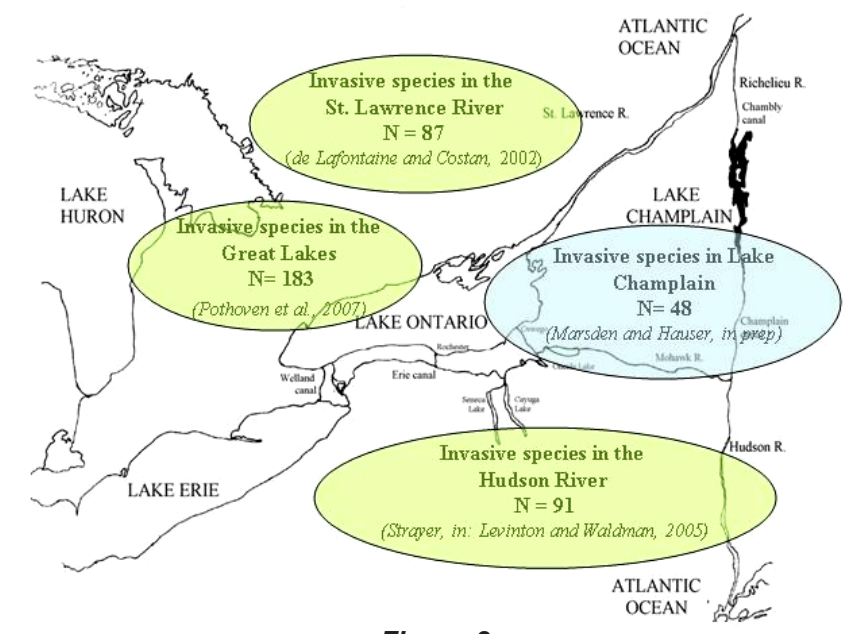

Figure 2

Aquatic invasive species pressures on the Lake Champlain Basin scientists, resource managers, policy makers, and local watershed organisations. The Subcommittee has worked to develop an Aquatic Invasive Species Rapid Response Management Plan (Plan). The Plan is modelled after other United States' state and regional plans and establishes a process for the three jurisdictions to respond to an invasion by lending resources and expertise regardless of the locations of the control actions.

\section{Lake Champlain basin background}

The Lake Champlain Basin is shared among the U.S. states of New York and Vermont and the Province of Quebec (Fig. 1). The watershed is bounded by the Adirondack Mountains to the west in New York and by the Green Mountains to the east in Vermont. Lake Champlain is a narrow, but long lake that drains the $21326 \mathrm{~km}^{2}$ watershed north out the Richelieu River in Quebec to the St. Lawrence sea-way. Lake Champlain is no more than $19 \mathrm{~km}$ wide and is over $122 \mathrm{~m}$ deep at its deepest point. The watershed has exceptional habitat diversity that supports over 80 species of fish, 40 species of reptiles and amphibians, and the region's largest diversity of fresh water mussels (14 species) (Lake Champlain Basin Program, 2003). Currently, there are 48 known aquatic invasive species in the Lake Champlain Basin.

The aquatic habitats of the Champlain basin have been altered by the construction of dams, transportation infrastructure, development, canals, floodplain encroachment, and the loss of riparian habitat in the last three centuries (Lake Champlain Basin Program, 2003). The disturbance, fragmentation, and alteration of both in-stream aquatic and riparian habitats coupled with the introduction of non-native species negatively impacts fish and wildlife resources and the economy and culture of the Lake Champlain basin.

\section{Aquatic invasive species problem in the Lake Champlain basin}

Aquatic invasive species have a competitive advantage over native species for food and habitat. In the Lake Champlain basin, aquatic invasive plants, such as water chestnut (Trapa natans) and Eurasian water milfoil (Myriophyllum spicatum), choke waterways and limit recreational use, displace native fish and plant species, and lower water oxygen levels. The cultural heritage of the region is threatened by invasive mussels like the zebra mussel (Dreissena polymorpha) clog water intake pipes for industrial and domestic water supplies, cut the feet of water recreationists, foul boat motors and dock equipment and encrust historical ship wrecks (Lake Champlain basin Program et al., 2005). Additionally, invasive fish species like the alewife (Alosa pseudoharengus), which are free of natural predators, disrupt the food chain and threaten already suppressed native species and popular sport fish which attract economic interests such as competitive fishing derbies. New fish-borne pathogens, such as viral hemorrhagic septicaemia, introduced by invasive fish species, especially bait fish, now threaten entire fisheries in the region. Water resource managers spend a significant amount of effort and financial resources to contain, control, and reduce the spread of invasive species (Malchoff et al., 2005).

The number of known aquatic invasive species in the Lake Champlain Basin is relatively low compared to adjacent waterways (Fig. 2). Lake Champlain is connected to the St. Lawrence River and Great Lakes system through the Chambly Canal in Quebec and it is also connected to the Hudson River and Erie Canal system through the Champlain Canal in New York. Currently there are 48 known aquatic invasive species in the Lake Champlain basin while there are 183 known aquatic invasive species in the Great Lakes (Pothoven et al., 2007), 87 in the St. Lawrence River (de Lafontaine and Costan, 2002), and 91 in the Hudson River (Strayer, in: Levinton and Waldman, 2005). The elevation change between the Lake Champlain basin and the other surrounding watersheds may be one reason why the Basin has only a fraction of the invasive species found in the Great Lakes system.

The number of invasive species introduced into the Lake Champlain basin is increasing each decade (Fig. 3). Since 2000 five new invasive species have entered the Lake Champlain basin. Fish stocking, bait fish release, and the canal waterway are the main vectors of introduction of the known aquatic invasive species in the Lake Champlain basin (Marsden et al., 2005). Current invasive species management in the basin relies on early detection and rapid-response efforts, spread prevention, and education and outreach

\section{Lake Champlain basin program}

Formed by the Lake Champlain Special Designation Act of 1990 and renewed by Congress in 2002, the Lake Champlain Basin Program is a public-private partnership among the US states 


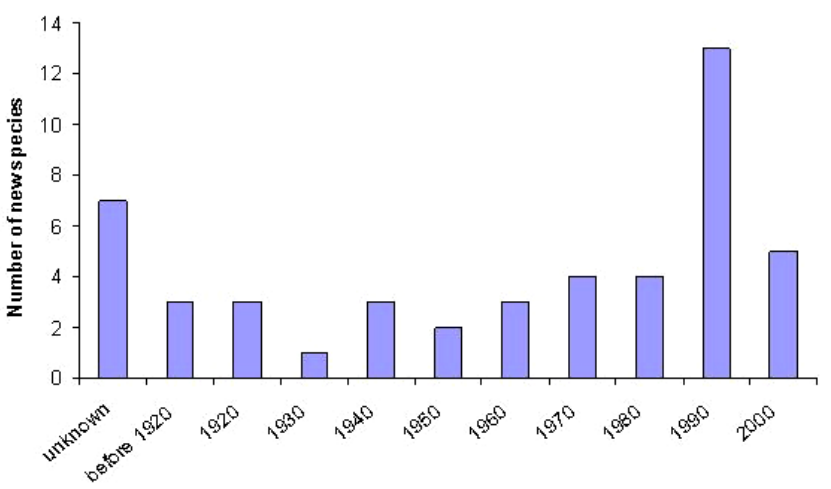

Figure 3

Arrival of 48 aquatic invasive species to the Lake Champlain Basin by decade. Figure adapted from Marsden et al. (2005)

of Vermont, New York and the Canadian Province of Quebec, USEPA, other federal and local agencies, and many local groups. The Lake Champlain Basin Program works cooperatively with its partners to protect and enhance the environmental integrity and the social and economic benefits of the international Lake Champlain Basin.

The Lake Champlain Basin Program has worked with its partners to develop a long-term management plan for the watershed: Opportunities for Action: An Evolving Plan for the Future of the Lake Champlain Basin. It took five years to write the initial plan which was published in 1996 and revised in 2003. The partnerships developed in the process of writing the plan helped create mutual understanding and set common goals. One of the four highest priority actions in the plan is to, 'control the introduction, spread, and impact of non-native nuisance species in order to preserve the integrity of the Lake Champlain ecosystem' (Lake Champlain Basin Program, 2003). Over a decade of history and partnership has enabled multiple agencies with differing views to develop the Aquatic Invasive Species Rapid Response Plan.

The Lake Champlain Basin Program's operating structure includes a Steering Committee that is charged with facilitating communication between partners, tracking progress in Opportunities for Action, and securing and directing program funding. The Steering Committee includes members from various agencies from Vermont, New York, and Quebec and receives technical advice from the Technical Advisory Committee, Executive Committee, Cultural Heritage and Recreation Advisory Committee, Education and Outreach Committee and citizen advisory committees from each jurisdiction.

The Lake Champlain Basin Program and its partners developed an Aquatic Nuisance Species Management Plan which was reviewed and approved by the National Aquatic Nuisance Species Task Force. Working with the States of Vermont and New York, the U.S. Fish and Wildlife Service and other partners, the Lake Champlain Basin Program recently revised the Lake Champlain Basin Aquatic Nuisance Species Management Plan (Lake Champlain Basin Program, 2005).

To further the goals of the Lake Champlain Basin Aquatic Nuisance Species Management Plan, the Lake Champlain Basin Program Technical Advisory Committee formed an Aquatic Nuisance Species Subcommittee. The Aquatic Nuisance Species Subcommittee is an advisory committee to the Technical Advisory Committee that addresses aquatic invasive species issues. The Aquatic Nuisance Species Subcommittee has two workgroups: the Rapid Response Workgroup that has developed the Lake Champlain Basin Aquatic Invasive Species Rapid Response Management Plan (Plan) and, the Spread Prevention Workgroup that focuses on invasive species education and outreach initiatives. The Aquatic Nuisance Species Subcommittee's charge is to coordinate and implement priorities in the Lake Champlain Basin Aquatic Nuisance Species Management Plan.

The Aquatic Nuisance Species Subcommittee's Rapid Response Workgroup developed a rapid response management plan for invasive aquatic species in the Basin in response to the economic, social, and political impacts of new aquatic invasive species introductions. Members of the committee include lake managers, policy makers, scientists, academics, and local watershed groups. Species of particular interest and concern include those already present, such as water chestnut (Trapa natans) and zebra mussel (Dreissena polymorpha) and those currently found in neighbouring water bodies, such as hydrilla (Hydrilla verticillata) and quagga mussel (Dreissena bugensis).

The Rapid Response Workgroup has met monthly since 2005 to identify key stakeholders, utilise existing resources, identify gaps between new technology and existing laws and policy, and share information and data to develop a comprehensive plan for the Lake Champlain basin. The goal of the rapid response planning process is to bring together resources from all jurisdictions to address infestations independent of where they occur in the basin. Partnering with other organisations has allowed the strategic invasive species rapid response planning to build on managers' and policy-makers' concerns, provide options, foster inter-jurisdictional cooperation, and consider the social, economic and political impacts of invasive species management.

\section{Lake Champlain basin aquatic invasive species rapid response management structure}

The Lake Champlain Basin Aquatic Invasive Species Rapid Response Management Plan is intended to ensure and facilitate the availability of appropriate protocols, trained personnel, equipment, permits, and other resources to contain or potentially eradicate newly detected non-native aquatic plant or animal introductions as they are reported or discovered in the Basin. The Plan is an administrative blueprint for appropriate state, federal and provincial agencies to work in partnership to facilitate rapid control or eradication of invasive species.

\section{Lake Champlain basin aquatic nuisance species rapid response task force}

The Plan suggests the formation of an inter-jurisdictional Lake Champlain Basin Rapid Response Task Force (RR Task Force) that would help implement and oversee rapid response actions. The role of the RR Task Force would be to facilitate and promote cooperation among jurisdictions responding to infestations of aquatic non-native invasive species in the Lake Champlain Basin. It serves to bring together technical experts to share information, management techniques and education and outreach materials. In addition, the RR Task Force will act to adapt the Plan and test the model with hypothetical infestations. Overall, the RR Task Force provides the network that is capable of mobilising resources from cooperating agencies in the three different jurisdictions to execute rapid response actions and efficiently address invasive species infestations.

The Lake Champlain RR Task Force would be comprised of resource managers and technical experts from Vermont, New 
York, and Quebec with each jurisdiction having a lead agency to coordinate efforts. Lead agencies would work closely with the RR Task Force to use resources most efficiently to implement rapid response actions including eradication, spread prevention, and monitoring of invasive species. The lead agencies are the Vermont Agency of Natural Resources for Vermont, the New York State Department of Environmental Conservation for New York, and the Quebec Ministry of Environment for the province of Quebec.

The RR Task Force and lead agency will work with the Adirondack Park Agency, Departments of Transportation, the U.S. Army Corps of Engineers, United States Coast Guard, and state departments of environmental conservation and fish and wildlife regarding any relevant general use permits. The Nature Conservancy and other non-governmental organisations may also be consulted for their expertise.

\section{Lake Champlain basin aquatic invasive species rapid response plan}

The Rapid Response Workgroup reviewed other state and regional invasive species rapid response management plans before designing one that would work best for the Lake Champlain basin. A five-step plan was created that outlines the process and permitting requirements if a new invasive species is found or if an existing invasive species spreads to a new area of the basin. The plan identifies a clear process to respond to an invasive species infestation including species identification, evaluation of eradication possibility and feasibility, permitting processes, monitoring, reporting, and spread prevention. The five steps of the plan are:

Step I: Species Confirmation

Step II: Delineation, Isolation and Preliminary Evaluation

Step III: Treatment, Selection and Design

Step IV: Treatment Plan Implementation

Step V: Monitoring and Evaluation

The Lake Champlain Basin Rapid Response Plan adopts the National Invasive Species Council definition of rapid response: 'a systematic effort to eradicate, contain, or control a potentially invasive non-native species introduced into an ecosystem while the infestation of that ecosystem is still localised.' Rapid response may encompass both new introductions and satellite infestations of previously established species. To achieve a rapid response, the agencies and organisations cooperating under the administrative blueprint provided by this plan will strive for eradication as the primary goal of all rapid response deployments, but will be prepared to shift to a long-term 'management' strategy if necessary. They will also commit to make decisions that reflect sound biology and site-specific conditions, facilitate fast action and interagency decision-making at the lowest level possible, minimise restrictions on water use, public access, parks, and other facilities, be fair and safe to all users, use personnel and resources efficiently, and be flexible, varying the protocol to accomplish steps concurrently and efficiently.

The plan includes a priority species list. The list of aquatic invasive plants, animals, and pathogens is not comprehensive, but includes examples of species that would trigger the rapid response process. The workgroup chose to include a few of the better known invasive species in the region on the priority list in order to attract legislative interest and support, while not overwhelming a given audience.

Descriptions for permit processes are outlined for all state, federal, and provincial agencies with jurisdiction in the Lake
Champlain basin related to aquatic invasive species rapid response actions including the Vermont Department of Environmental Conservation, New York State Department of Environmental Conservation, Adirondack Park Agency, Vermont Department of Fish and Wildlife, United States Army Corps of Engineers, and the Quebec Ministry of Environment. The availability of all the jurisdiction's permitting information will help facilitate rapid response actions by providing a prospective applicant for an invasive species rapid response permit with all the resources and contact information required. The RR Workgroup found that reviewing the appropriate permitting processes also helped partners to identify opportunities to improve legislation.

\section{Rapid response five-step process}

\section{Step I: Species Confirmation}

The plan provides a process for identifying a new invasive species within the basin. Taxonomic experts from the three jurisdictions have been identified and listed within the plan. In addition, experts from beyond the Basin are listed on the National ANS Task Force website (http://www.anstaskforce.gov/experts/ search.php). Species confirmation is to occur by the end of week one of a reported species finding.

\section{Step II: Delineation, Isolation and Preliminary Evaluation}

The lead agency determines and maps the extent of the infestation. Preliminary actions are taken to limit the dispersal of the invasive species. The lead agency and RR Task Force evaluate the threat, risk of spread, and potential for eradication by completing the Species Evaluation Questionnaire.

The Species Evaluation Questionnaire is included in the plan and is a tool to standardise an evaluation of risk for each species reviewed. Estimates of the potential for invasive species impact and the potential for management under a number of parameters are rated and scored. The risk screening value is relative and does not express a specific management strategy, but is considered by the RR Task Force when developing a rapid response action plan. The questionnaire was adopted from the Massachusetts Department of Environmental Protection.

Although timeliness is a key element in rapid response, 'rapid' time frames vary based on species-specific variables such as reproductive rates, ability of a vector to transmit a disease agent, and likelihood and method of spread. In some instances, a species may become invasive after only a few days and require immediate action. In other instances, for example with some plant species, longer response times may be acceptable due to their reproductive cycle and sedentary nature.

The lead agency and RR Task Force will determine if eradication is warranted and technically possible and if it is feasible. A feasible eradication determination forwards the rapid response process to Step III: Treatment Selection and Design. If eradication is not possible or feasible the RR Task Force will take immediate spread-prevention actions and end the rapid response process.

\section{Step III: Treatment, Selection and Design}

The third step requires the RR Task Force and lead agencies to evaluate treatment options, seek advice from other agencies, and begin the permitting process as soon as possible. Often the lead agency will develop the treatment plan in consultation with the RR Task Force. If a permit is required the lead agency will identify the applicant and the applicant will proceed with the permit 
application and treatment activities. If no permit is required the treatment plan may be implemented immediately.

\section{Step IV: Treatment Plan Implementation}

The lead agency consults internal operation procedures and conducts the treatment. The lead agency will implement the plan as necessary and solicit and coordinate volunteers and consultants, prepare the staging site, materials, and equipment, and establish safety and communication protocols. The implementation of the treatment plan will be overseen by the lead agency, but all jurisdictions will contribute resources and expertise if needed.

\section{Step V: Monitoring and Evaluation}

After the treatment plan implementation the lead agency will monitor the effectiveness of the rapid response treatment. The lead agency is responsible for reporting the evaluation results and recommendations for future action to the RR Task Force, state and provincial agencies, and public stakeholders. If the infestation persists, the lead agency will develop a long-term management and spread prevention plan.

\section{Next steps}

\section{Turning innovative thinking into success for all partners/jurisdictions}

Once all the technical experts have been identified, major agencies represented, and the invasive species management plan has been completed, the plan requires endorsement. It will be brought up through the Lake Champlain Basin Program process which has Steering Committee co-chairs that sit on the Vermont and New York Departments of Environmental Conservation and the Quebec Ministry of Environment.

The plan can take action through the signing of a nonbinding, consensus-based memorandum of understanding between all three jurisdictions. The memorandum of understanding will commit staff and resources of the three jurisdictions to invasive species management in the entire Lake Champlain basin and endorse the formation of the Lake Champlain Basin Rapid Response Task Force.

\section{Conclusions}

The Lake Champlain basin inter-jurisdictional approach to watershed management for invasive species serves as an example for other HELP basins around the world. The process of developing interstate, international, interagency plans to address significant environmental issues allows actions to occur more quickly. The Lake Champlain Basin Aquatic Invasive Species Rapid Response Plan provides the opportunity to save a significant amount of money when addressing species that pose ecological and economic harm to the region.

The Rapid Response Workgroup has reviewed permitting processes of all regulatory agencies that hold jurisdiction in the
Lake Champlain basin and identified the best technologies to control or prevent the spread of invasive species. They key to responding rapidly is to foster dialogue between permit applicants, scientists, and regulating agencies. Gathering all available laws and policy together to understand how they interface with permitting requirements, control, and management is essential to interstate and international water resource management. The review of such laws and policies can help to identify gaps in existing legislation and create more comprehensive legislation in the future.

The creation of a RR Task Force and the development of the rapid response management plan allows Vermont, New York, and Quebec to respond quickly and in a coordinated fashion to new invasions. When caught early the likelihood of treatment, management, and even eradication are much higher and less expensive.

The participatory process of the Lake Champlain Basin Aquatic Invasive Species Rapid Response Plan ensures that all parties have an equal voice at the table and all views and concerns can be incorporated into the plan. With legislative endorsement from the three jurisdictions this plan will open up a deeper partnership that will fuel the sharing of technology, new science, law, policy, and user views and will help to better manage the basin's resources.

\section{References}

DE LAFONTAINE Y and COSTAN G (2002) Introduction and transfer of alien aquatic species in the Great Lakes-St. Lawrence River basin. In: Alien Invaders in Canada's Waters, Wetlands, and Forest. Natural Resources Canada, Ottawa, Ontario. 103-110.

LAKE CHAMPLAIN BASIN PROGRAM (2003) Opportunities for Action: An Evolving Plan for the Future of the Lake Champlain Basin. Lake Champlain Basin Program, Grand Isle, VT, USA.

LAKE CHAMPLAIN BASIN PROGRAM (2005) State of the Lake: Lake Champlain in 2005, a Snapshot for Citizens. Lake Champlain Basin Program, Grand Isle, VT, USA.

LAKE CHAMPLAIN BASIN PROGRAM, VERMONT DEPARTMENT OF ENVIRONMENTAL CONSERVATION, NEW YORK STATE DEPARTMENT OF ENVIRONMENTAL CONSERVATION (2005) Lake Champlain Basin Aquatic Nuisance Species Management Plan. Lake Champlain Basin Program, Grand Isle, VT, USA.

MALCHOFF M, MARSDEN JE and HAUSER M (2005) Feasibility of Champlain Canal Aquatic Nuisance Species Barrier Options. Lake Champlain Sea Grant, Plattsburgh, NY, USA.

MARSDEN JE, MALCHOFF M and HAUSER M (2005) Investigation of the need and options for an exotic species barrier on the Champlain Canal. Aquat. Invaders 16 (3) 11-14.

NONINDIGENOUS AQUATIC NUISNACE PREVENTION AND CONTROL ACT of 1990 (P.L. 101-646).

POTHOVEN SA, GRIGOROVICH IA, FAHNENSTIEL GL and BLACER MD (2007) Introduction of Ponto-Caspian bloody-red mysid Hemimysis anomala into the Lake Michigan basin. J. Great Lakes Res. 33 285-292.

STRAYER DL (2005) Alien species in the Hudson River. In: JS Levinton and Waldman JR (eds.) The Hudson River Estuary. Oxford University Press, Oxford. 